\title{
The effect of hybrid steel fiber on the properties of fresh and hardened self-compacting concrete
}

\author{
Haddadou $\mathrm{N}^{*}, 1$, Chaid $\mathrm{R}^{2}$, Ghernouti $\mathrm{Y}^{2}$ and Adjou $\mathrm{N}^{1}$
}

\author{
1 National Center of Studies and Integrated Research on Building Engineering (CNERIB), Cité Nouvelle El- \\ Mokrani, Souidania, Algiers, Algeria. \\ 2 Research Unit: Materials, Processes and Environment, University M'Hamed Bougara of Boumerdes, Algeria. \\ Corresponding Author: haddadounai@yahoo.fr
}

\begin{abstract}
Self-compacting concrete (SCC) offers several economical and technical benefits, the use of steel fibers extends its possibilities. This study was performed to compare the properties of SCC and fiber reinforced self-compacting concrete (FRSCC) with high volume of mineral addition. Six mixtures were elaborated in this study. The content of the cementitious materials and the water/cementitious materials ratio were kept constant, $500 \mathrm{~kg} / \mathrm{m}^{3}$ and 0.34 respectively.

The self-compacting mixtures have been prepared with a cement replacement of $30 \%$ by weight of marble powder. Two different types of steel fibers were used in combination with different lengths $\left(50 \mathrm{~mm}\right.$ and $30 \mathrm{~mm}$ ), keeping the total fiber content constant at $60 \mathrm{~kg} / \mathrm{m}^{3}$. Slump flow time and diameter, sieve stability, and L-Box were performed to assess the fresh properties of the SCC and FRSCC. Compressive strength, splitting tensile strength, flexural strength and ultrasonic pulse velocity were determined for the hardened properties. A marginal improvement in the ultimate strength was observed. The addition of steel fiber enhanced the ductility significantly and the results indicated that high-volume of marble powder can be used to produce FRSCC, even though there is some decrease in the compressive strength because of the fiber geometry which affects the properties of SCC mixtures not only in the fresh state but also in the hardened state.
\end{abstract}

Key words: Self-compacting concrete, marble powder, steel fiber, hybrid fiber, workability, strength.

\section{Introduction}

In the present time, the constructions in civil engineering have their own structural and durability requirements of the concrete, which can accommodate the intended function of the structure. It is therefore necessary to develop self-compacting concrete (SCC) of special properties, so that the structures continue to perform their intended purpose. SCC has an excellent applicability for elements with complicated shapes and congested reinforcement. Consequently, SCC has been recently one of the most important developments in the construction industry (Brouwers and Radix, 2005). One of the disadvantages of SCC is the cost, associated with the usage of chemical admixtures and the high volume of portland cement. As an alternative to reduce the cost of SCC is the usage of mineral additives (such as marble powder, natural pozzolan, fly ash and slag) which are finely divided materials added to concrete as separate ingredients either before or during mixing (Şahmaran, 2006). The compactness of the SCC matrix, due to the higher amount of fine and extra-fine particles, may improve interface zone properties (Corinaldesi and Moriconi, 2004; Moriconi and Corinaldesi, 2005), leading to enhanced post-cracking toughness and energy absorption capacity.

The addition of steel fibers improves the mechanical properties and the ductility of SCC in much the same manner as in vibrated concrete. However, the fibers greatly impair the workability of SCC because of their elongated shape and large surface area. The development and the usage of SCC have resolved the workability issue. The applicability of steel fibers with SCC has been investigated and has proven to be feasible (Ding, 2010; Ding, 2011). The properties of fibers that are usually of interest are; fiber concentration, fiber geometry, fiber orientation and fiber distribution. Fibers which are basically longer need particles to have a significant influence 
consistency and a workability of fresh concrete mix. Apart from the sheer volume of added fibers. This influence depends on both properties of fibers (aspect ratio of a fiber, characterized by rigidness/flexibility ratio and roughness of a surface) and properties of concrete (paste volume, maximum aggregate size, shape of aggregate particles). Hooked steel fibers proved to be a very good solution for enhancing limited mechanical properties of concretes (Katzer, 2008; Domeski, 2011). The effect of mineral admixtures on the strength and durability of fiber reinforced self-compacting concrete (FRSCC) has been extensively investigated under different environmental conditions (Corinaldesi and Moriconi, 2004; Sahmaran and Yaman, 2007; Srinivasa, 2009). The investigation of the FRSCC by the researchers shows improvement of the mechanical properties in terms of apparent compressive strength, flexural strength, splitting tensile strength, elastic modulus, creep and shrinkage, shear and pullout behavior, as compared to normally vibrated concrete, SCC and fiber reinforced normally vibrated concrete under statically applied loads (Sahmaran and Yaman, 2007; Ambroise, 2001; Dhonde, 2007; Greenough and Nehdi, 2008; Torrijos, 2008; Cunha, 2009). The inherent advantages of FRSCC enhance the scope of its applications, especially in long span bridges, slabs, highway pavements and offshore platforms for oil production in the deep sea where the predominant mode of loading is flexural fatigue.

The objective of this study is to assess the effects of marble powder (MP) replacement on the fresh and hardened properties of SCC incorporating different length of steel fibers. Even though, the suitability of MP in FRSCC needs much detailed investigations, this study covers some fresh and hardened properties of such mixtures. In addition to the MP, two different type and sizes of steel fibers were used at different proportions in making the concrete. The total mass of cementitious materials was $500 \mathrm{~kg} / \mathrm{m}^{3}$, in which $30 \%$ of cement is replaced by MP. For comparison, a control SCC mixture without steel fiber was also produced.

\section{Experimental procedure}

\subsection{Materials}

A CEMII/A 42.5 cement type and a limestone type MP were used as binder materials in the mix proportions. The chemical properties of cement and marble powder are given in Table 1 whereas the mineralogical composition of cement is given in Table 2. Figures 1 and 2 presented the mineralogical composition of cement and marble powder determined by X-ray diffraction.

Table 1. Chemical composition of Cement and Marble.

\begin{tabular}{|c|c|c|}
\hline Element & Cement & MP \\
\hline \hline $\mathrm{S}_{\mathrm{i}} \mathrm{O}_{2}$ & 16,52 & 0.34 \\
\hline $\mathrm{Al}_{2} \mathrm{O}_{3}$ & 4,08 & 0.04 \\
\hline $\mathrm{Fe}_{2} \mathrm{O}_{3}$ & 2,89 & 0.13 \\
\hline $\mathrm{CaO}$ & 58,49 & 54.93 \\
\hline $\mathrm{MgO}$ & 1,47 & 0.73 \\
\hline $\mathrm{K}_{2} \mathrm{O}$ & 0,47 & 0.01 \\
\hline $\mathrm{Na}_{2} \mathrm{O}$ & 0,24 & 0.01 \\
\hline $\mathrm{SO}_{3}$ & 1,98 & 0.06 \\
\hline $\mathrm{TiO}_{2}$ & 0,22 & 0.01 \\
\hline $\mathrm{P}_{2} \mathrm{O}_{5}$ & 0,14 & 0.02 \\
\hline Insoluble & 1,09 & $/$ \\
\hline Loss of ignition & 7,45 & 43.72 \\
\hline
\end{tabular}

Table 2. Mineralogical Composition of Cement.

\begin{tabular}{|c|c|}
\hline Element & $(\%)$ \\
\hline \hline $\mathrm{C}_{3} \mathrm{~S}$ & 56 \\
\hline $\mathrm{C}_{2} \mathrm{~S}$ & 20 \\
\hline $\mathrm{C}_{3} \mathrm{~A}$ & 05 \\
\hline $\mathrm{C}_{4} \mathrm{AF}$ & 13 \\
\hline
\end{tabular}




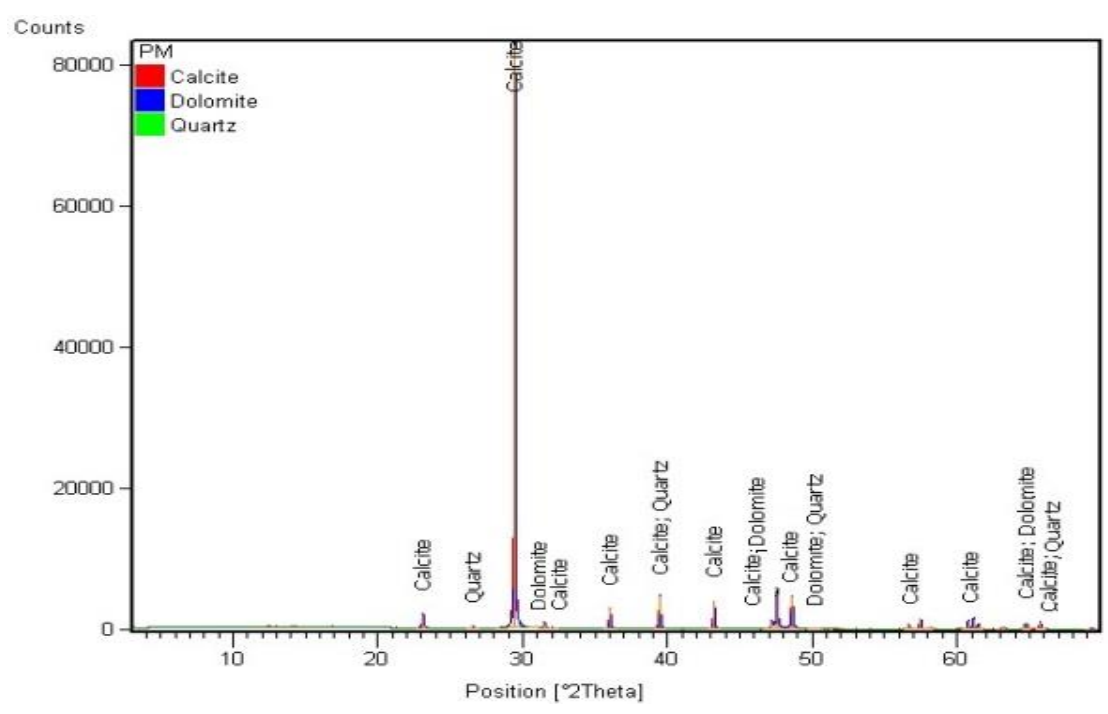

Fig 1. X-ray diffraction pattern of MP.

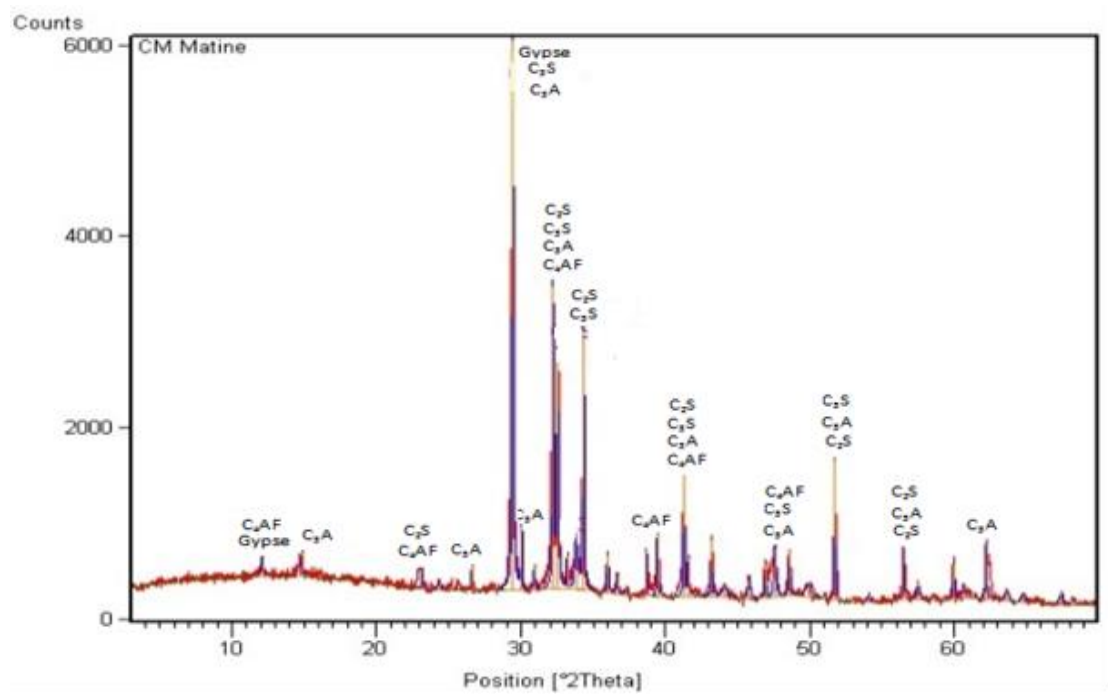

Fig 2. X-ray diffraction pattern of cement.

In order to determine the surface characteristics of MP, scanning electron microscopy was performed and the typical secondary electron image is presented in Fig. 3. As seen in this figure, MP grains show angular shapes with a rough surface texture.

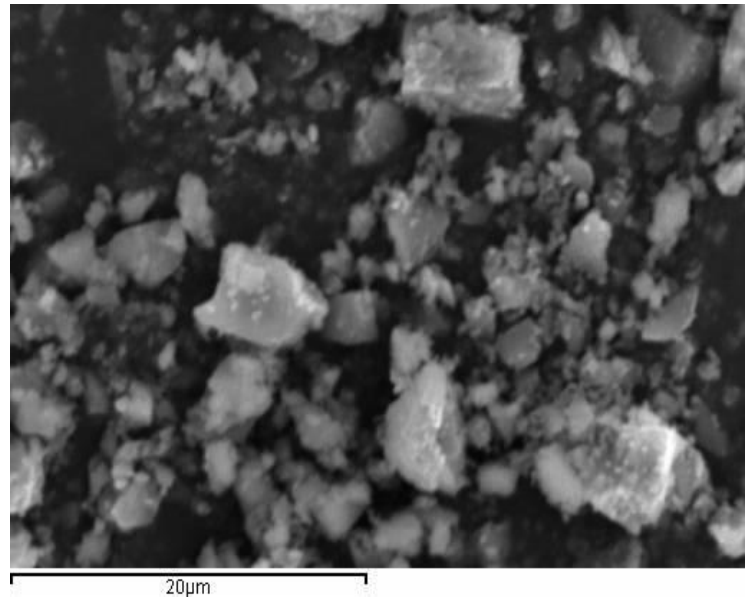

Fig 3. Scanning electron microscopy (SEM) of MP. 
Workability improvement of SCC mixtures was obtained thanks to the polycarboxylates superplasticizer (Medaflow 30) characterized by a chloride content lower than $0.1 \%$ and a viscosity modifying admixture (Medacol BSE). The properties of both admixtures, as provided by their manufactures, are shown in Table 3 . Continuously graded coarse aggregates $(3 / 8$ and $8 / 15$ ) were used with specific gravity and water absorption of $2.56 \mathrm{~g} / \mathrm{cm}^{3}$ and $1.03 \%$ respectively. Natural dune sand and river sand were used. Selected sands are subjected to grain size distribution analysis as per XP P 18-540 standard (AFNOR, 1997). Physical properties of used sands are given in Table 4. The gradation of coarse and fine aggregates was determined by sieve analysis and presented in Figure 4.

Table 3. Properties of Chemical Admixture.

\begin{tabular}{|c|c|c|l|c|l|}
\hline $\begin{array}{l}\text { Chemical } \\
\text { admixture }\end{array}$ & $\begin{array}{l}\text { Specific } \\
\text { gravity }\end{array}$ & \multicolumn{1}{l|}{$\mathrm{pH}$} & Color & Dosage $\left(1 / \mathrm{m}^{3}\right)$ & Main component \\
\hline \hline SP & 1,06 & 5,3 & Light brown & 0,3 to 2 & carboxylic ether \\
\hline VMA & 1,03 & 6.2 & Light yelow & 0.5 to 2 & $\begin{array}{c}\text { Aqueous dispersion of } \\
\text { microscopic silica }\end{array}$ \\
\hline
\end{tabular}

Table 4. Properties of used Sands (DS and RS).

\begin{tabular}{|c|c|c|}
\hline & DS & RS \\
\hline \hline Fineness modulus & 1.29 & 2.85 \\
\hline Sand equivalent & 48 & 90 \\
\hline Absorption (\%) & 2.43 & 0.63 \\
\hline Moisture content (\%) & 1 & 0.42 \\
\hline
\end{tabular}

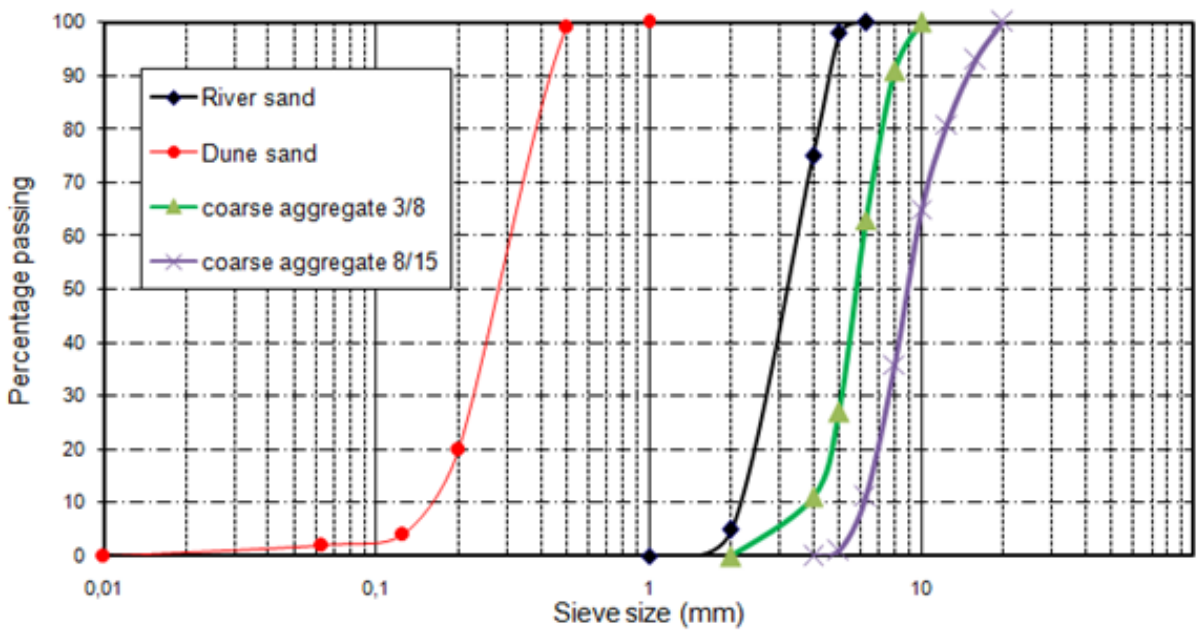

Fig 4. Particle size distribution of coarse and fine aggregates.

The first type of fibers used in this research is corrugated steel with low strength (LS) and the second type is Hooked-ended steel fibers (HS) with $50 \mathrm{~mm}$ in length and $0.55 \mathrm{~mm}$ diameter. The reason for using LS steel is that it's accessible with low cost. These fibers have been used with a rectangular section and length $\mathrm{L}=30 \mathrm{~mm}$. As long as the influence of this type of corrugated steel fiber is more than simple fiber (Okamura and Ouchi, 2003). That's why all the fibers are shaped with machine in sinusoidal wave as shown in Fig.5.a.

\subsection{Mixture proportions}

Six mixtures, one SCC and five FRSCC, were prepared for investigating the effect of type and sizes of steel fibers. Water/ (fine materials) ratio was fixed at 0.34 for all concrete mixtures. All of the mixtures had the same amount of marble powder $30 \%$ replaced by weight of cement. These were named as SCC, RSCC1, RSCC2, RSCC3, RSCC4 and RSCC5 indicating the two different values 
of aspect ratios, and the same percentage of volume fraction of steel fiber incorporated in the mixture $\left(60 \mathrm{~kg} / \mathrm{m}^{3}\right)$.

(a)

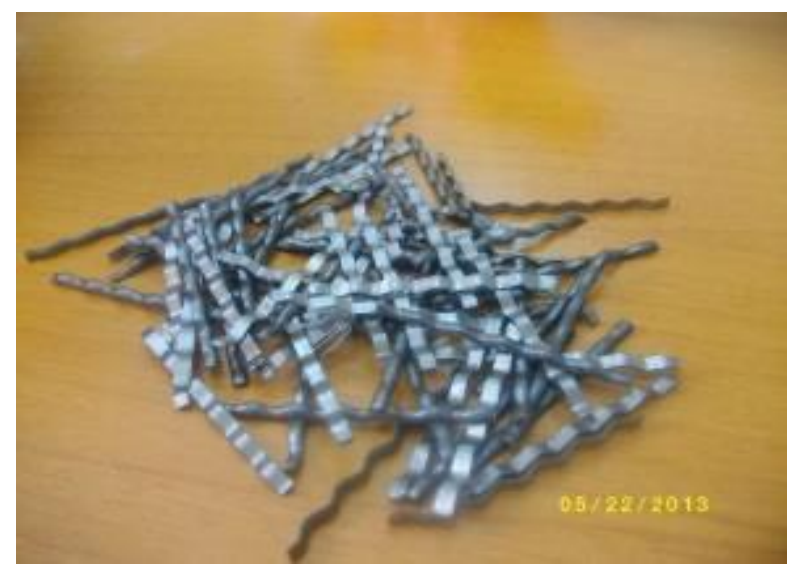

(b)

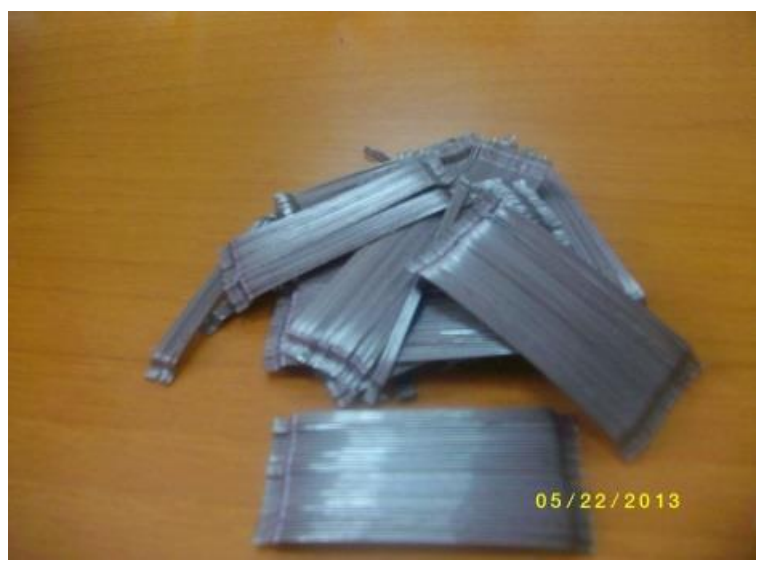

Fig 5. Steel fibers used for the production of FRSCC (a):LS, (b):HS.

For all the mixtures, the total amount of binder, water and the amount of steel fiber were all kept constant as seen in Table 5. The chemical admixture was added to the mixture until the SCC characteristics were obtained.

Table 5. Mix Proportions.

\begin{tabular}{|c|c|c|c|c|c|c|c|c|c|c|}
\hline \multirow{2}{*}{ Mix ID } & \multirow{2}{*}{$\mathrm{W} / \mathrm{B}$} & \multirow{2}{*}{$\begin{array}{l}\mathrm{C} \\
\left(\mathrm{kg} / \mathrm{m}^{3}\right)\end{array}$} & \multirow{2}{*}{$\begin{array}{l}\mathrm{MP} \\
\left(\mathrm{kg} / \mathrm{m}^{3}\right)\end{array}$} & \multicolumn{2}{|c|}{$\begin{array}{l}\text { Fine aggregate } \\
\left(\mathrm{kg} / \mathrm{m}^{3}\right)\end{array}$} & \multirow{2}{*}{$\begin{array}{l}\text { Coarse } \\
\text { aggregate } \\
\left(\mathrm{kg} / \mathrm{m}^{3}\right)\end{array}$} & \multicolumn{2}{|c|}{ Fibers $\left(\mathrm{kg} / \mathrm{m}^{3}\right)$} & \multirow{2}{*}{$\begin{array}{l}\mathrm{SP} \\
\left(\mathrm{l} / \mathrm{m}^{3}\right)\end{array}$} & \multirow{2}{*}{$\begin{array}{l}\text { VMA } \\
\left(1 / \mathrm{m}^{3}\right)\end{array}$} \\
\hline & & & & $0 / 1$ & $0 / 5$ & & LS 30 & HS 50 & & \\
\hline SCC & 0.34 & 350 & 150 & 173 & 610 & 790 & 0 & 0 & 5.9 & 1.43 \\
\hline RSCC1 & 0.34 & 350 & 150 & 190 & 720 & 717 & 60 & 0 & 5.9 & 1.43 \\
\hline RSCC2 & 0.34 & 350 & 150 & 190 & 720 & 717 & 42 & 18 & 5.9 & 1.43 \\
\hline RSCC3 & 0.34 & 350 & 150 & 190 & 720 & 717 & 30 & 30 & 5.9 & 1.43 \\
\hline RSCC4 & 0.34 & 350 & 150 & 190 & 720 & 717 & 18 & 42 & 5.9 & 1.43 \\
\hline RSCC5 & 0.34 & 350 & 150 & 190 & 720 & 717 & 0 & 60 & 5.9 & 1.43 \\
\hline
\end{tabular}

\subsection{Preparation and casting of test specimens}

In the production of SCC, mixing sequence and duration are very important, thus the mixing process was kept constant for all concrete mixtures. The following mixing sequence was arrived after several trials for optimizing the workability. All the ingredients were first mixed in dry condition in the concrete mixer for one minute. Then $70 \%$ of calculated amount of water was added to the dry mix and mixed thoroughly for one minute. The remaining $30 \%$ of water was mixed with the SP and VMA and was poured into the mixer and mixed for five minutes. At this stage, $20 \%$ by weight of the water mixed with SP was poured into mixer and mixed for four minutes. Then, $10 \%$ by weight of water mixed with VMA was poured into the mixer and mixed for one minute. Later required quantities of steel fiber were sprinkled over the concrete mix and mixed for one minute to get a uniform mix. Thus, the total mixing time was 7 minutes.

In this investigation the filling ability was evaluated by slump flow time and diameter. The passing ability was measured by L-Box. The resistance to segregation was measured by sieve stability test (EFNARC, 2005). For each concrete mixture six cubes of $150 \mathrm{~mm}$, six prisms of $70 * 70 * 280 \mathrm{~mm}$ and fifteen cylinders of $150 * 300 \mathrm{~mm}$ specimens were cast. 


\subsection{Tests on fresh concretes}

Slump flow time and diameter tests, L-Box and sieve stability test were carried out according to the limitations specified by EFNARC as shown in Fig.6. The first and second test procedures were discussed by Sahmaran and Yaman (2007) and are briefly described below. The slump flow is used to evaluate the horizontal free flow (deformability) of SCC in the absence of obstructions. The test method is very similar to the test method for determining the slump flow of concrete. The difference is that, instead of the loss in height, the diameter of the spread concrete is measured in two perpendicular directions and recorded as slump flow. The higher the slump flow, the larger is concrete's ability to fill formwork. During the slump flow test, the time required for the concrete to reach a diameter of $500 \mathrm{~mm}$ is also measured and recorded as $\mathrm{T}_{500}$. This parameter is an indication of the viscosity of concrete and indicates the stability of the concrete. A lower time points to a greater fluidity or smaller workability loss. According to Nagataki and Fujiwara (1995), a slump flow diameter ranging from 500 to $700 \mathrm{~mm}$ is considered as the slump required for a concrete to be classified as SCC. According to Specification and Guidelines for SCC prepared by EFNARC (2005) (European Federation of National Trade Associations), a slump flow diameter ranging from 650 to $800 \mathrm{~mm}$ can be accepted for SCC.

In addition to the slump flow test, L-Box test and sieve stability test are also performed to assess the flow ability, passing ability and stability of SCC. The L-Box ratio must be in the range of 0.81.0 and the sieve stability values must be in the range of 0-15\%. Good flowable and stable concrete would consume short time to flow out. According to Khayat and Guizani (1997), a good SCC has a flow times in the range of 0-5 sec.

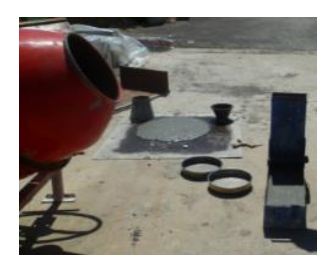

Workability

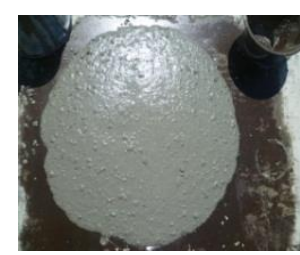

Slump flow test

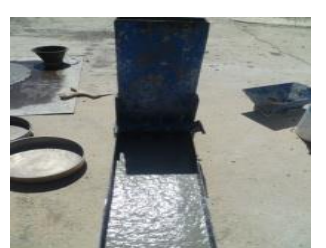

L-Box test

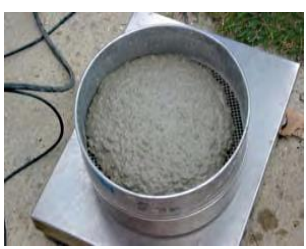

Seive stability test

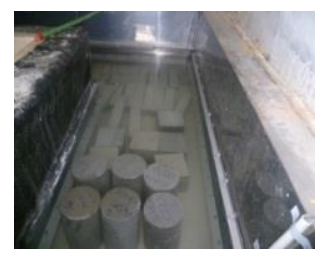

Conservation of specimens

Fig 6. Workability tests on SCC.

\subsection{Tests on hardened concrete}

Concrete specimens have been batched, moulded and cured according to EN 12390-2 (2001). All the moulds were covered by plastic sheets and stored for 24 hours in the laboratory prior to demoulding; afterwards, they were cured in water at $20^{\circ} \mathrm{C}$ and at relative humidity (RH) in the order of $50-60 \%$.

A testing programme has been elaborated and consisted of determining the essential properties of fresh and hardened SCC as shown in Fig.7. The necessary test specimens have been cast in different moulds and three tests were carried out to assess each required characteristic. For the determination of compressive strength and ultrasonic pulse velocity (UPV), concrete cubes of $150 * 150 * 150 \mathrm{~mm}^{3}$ (EN 12390-3, 2001; EN 12504-4, 2005) were used. It was measured at 7, 28 and 56 days old and to determine split tensile strength cylinder, specimens $150 * 300 \mathrm{~mm}^{3}$ (EN $12390-6,2001$ ) were used at 28 and 56 days old, using a testing machine with a maximum load capacity of $3000 \mathrm{kN}$.

The tensile strength was measured on $70 * 70 * 280 \mathrm{~mm}^{3}$ prismatic specimens (EN 12390-5, 2001) at 28 and 56 days old applying a three-point bending test, using a testing machine with a maximum load capacity of $100 \mathrm{kN}$. 

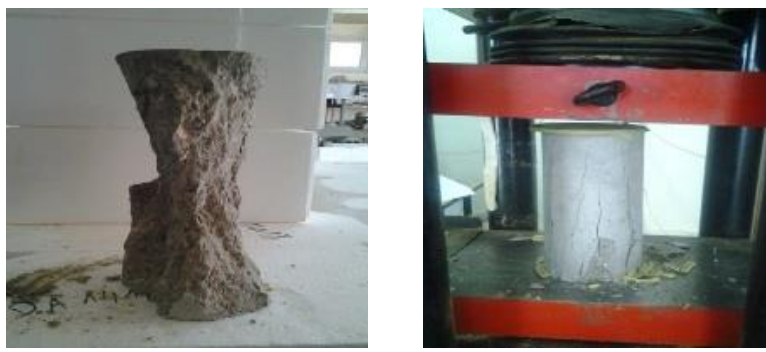

Compressive strength test
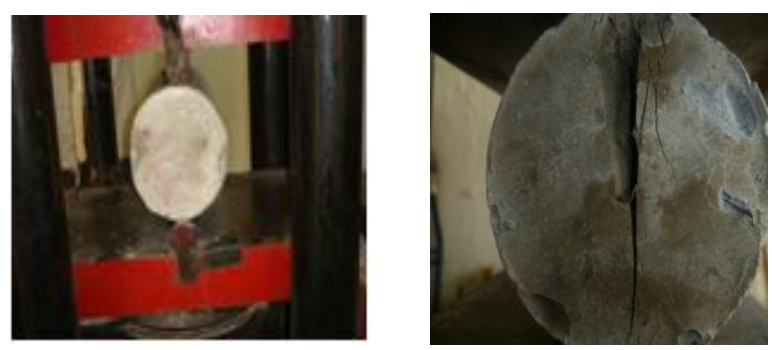

Split tensile strength

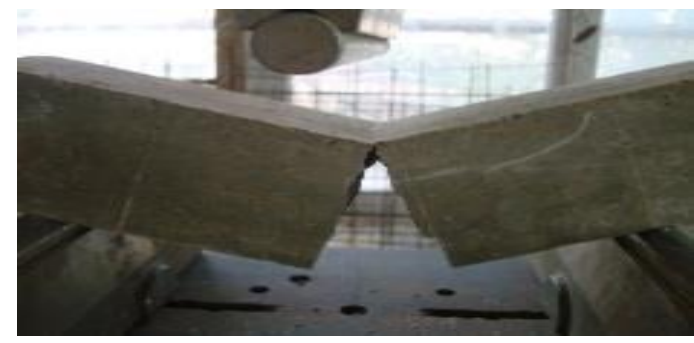

Flexural strength

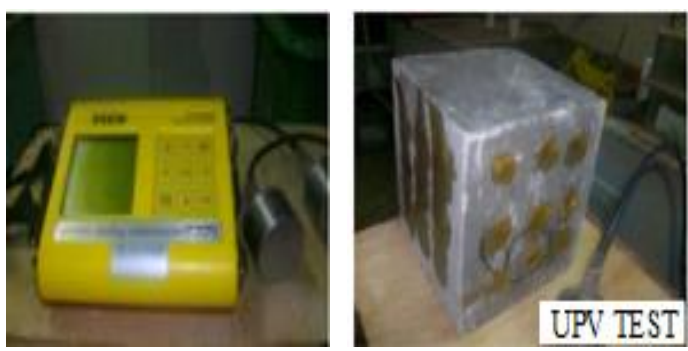

Ultrasonic pulse

Fig 7. Hardened tests on SCC.

\section{Results and discussions}

\subsection{Fresh concrete properties}

To classify a concrete as self-compacting, the requirements for filling and passing ability as well as segregation resistance must be fulfilled. It is specified that the filling ability and stability of SCC in the fresh state can be defined by four key characteristics namely flowability, viscosity, passing ability, and segregation resistance (Barr, 1996). Fresh properties of the concretes were carried out according to the limitations specified by EFNARC as shown previously in Fig.6. The results obtained are reported in Table 6 . As seen in this table, the fresh properties are in the range of 612-708 $\mathrm{mm}$ for slump flow diameters, 3.32-5.03s for slump flow times, 0.81-0.95 for the L-box ratio and 3.03-5.52\% for the sieve stability. All concrete mixtures were considered as Self compacting concrete (SCC). In all of the SCC mixtures, there was no segregation of aggregate near the edges of the spread-out concrete as observed from the slump flow test.

Table 6. Fresh properties of SCC.

\begin{tabular}{|c|c|c|c|c|}
\hline $\begin{array}{l}\text { Mix } \\
\text { ID }\end{array}$ & $\begin{array}{l}\text { Slump flow } \\
(\mathrm{mm})\end{array}$ & $\begin{array}{l}\text { T500 } \\
(\mathrm{s})\end{array}$ & $\begin{array}{l}\text { L-Box } \\
\text { ratio }\end{array}$ & $\begin{array}{l}\text { Sieve stability } \\
(\%)\end{array}$ \\
\hline \hline SCC & 708 & 3.32 & 0.95 & 5.52 \\
\hline RSCC1 & 705 & 4.06 & 0.92 & 4.9 \\
\hline RSCC2 & 700 & 4.23 & 0.93 & 4.62 \\
\hline RSCC3 & 675 & 4.51 & 0.89 & 4.12 \\
\hline RSCC4 & 648 & 4.86 & 0.83 & 4.22 \\
\hline RSCC5 & 612 & 5.03 & 0.81 & 3.03 \\
\hline
\end{tabular}

The MP can be considered as limestone filler which is one of the materials that have extensively been studied in the literature (Elkhadiri, 2002; Petit and Wirquin, 2010) and have improved the mechanical and durability features of concretes by providing more compact structure through its pore-filling effect. MP helps to evenly disperse fibers during mixing. Although the angular shapes with rough surface texture of MP particles provide ball bearing effects and reduce internal friction in fresh concrete and these increase the flowability and compaction of the concrete.

The steel fibers have affected slightly the fresh properties of the concrete mixtures. The addition of LS steel fibers did not affect the water requirement of the mixture for the same workability. However, addition of HS fibers which had large sizes reduced the amount of water, as seen in 
Table 6, the fresh properties decreased with the increase of HS fiber content. However, this could be explained by the geometry of the fibers. LS fibers have smaller dimensions when compared to HS fibers, thus have less potential to prevent the movement of aggregates. Therefore, the shorter size of fibers reduced the energy loss during the movement of concrete ingredients.

\subsection{Hardened concrete properties}

The hardened concrete test results are summarized in Table 7, which included compressive strength, split tensile strength, flexural strength and UPV at different ages.

Table 7. Hardened properties of SCC.

\begin{tabular}{|c|c|c|c|c|c|c|c|c|c|c|}
\hline \multirow{2}{*}{ Mix ID } & \multicolumn{3}{|l|}{$\begin{array}{l}\text { Compressive strenght } \\
\text { (MPa) }\end{array}$} & \multicolumn{3}{l|}{$\begin{array}{l}\text { Splitting tensile } \\
\text { strenght } \\
\text { (MPa) }\end{array}$} & \multicolumn{2}{l|}{$\begin{array}{l}\text { Flexural strenght } \\
\text { (MPa) }\end{array}$} & \multicolumn{3}{l|}{$\begin{array}{l}\text { Ultrasonic pulse } \\
\text { velocity (UPV) } \\
\text { (m/s) }\end{array}$} \\
\cline { 2 - 12 } & $7 \mathrm{~d}$ & $28 \mathrm{~d}$ & $56 \mathrm{~d}$ & $28 \mathrm{~d}$ & $56 \mathrm{~d}$ & $28 \mathrm{~d}$ & $56 \mathrm{~d}$ & $7 \mathrm{~d}$ & $28 \mathrm{~d}$ & $56 \mathrm{~d}$ \\
\hline \hline SCC & 28.63 & 35.45 & 38.56 & 2.32 & 2.68 & 4.45 & 4.79 & 3926 & 4038 & 4158 \\
\hline RSCC1 & 30.63 & 37.74 & 40.36 & 2.51 & 3.41 & 4.6 & 4.89 & 4098 & 4252 & 4398 \\
\hline RSCC2 & 29.45 & 35.78 & 38.25 & 2.72 & 3.84 & 5.08 & 5.28 & 4162 & 4292 & 4303 \\
\hline RSCC3 & 27.22 & 36.56 & 36.71 & 3.12 & 3.86 & 5.53 & 5.31 & 4208 & 4312 & 4377 \\
\hline RSCC4 & 26.57 & 33.62 & 37.41 & 3.52 & 4.22 & 5.49 & 5.97 & 4158 & 4271 & 4359 \\
\hline RSCC5 & 25.44 & 32.18 & 34.39 & 3.83 & 4.53 & 5.93 & 6.29 & 4247 & 4324 & 4358 \\
\hline
\end{tabular}

To evaluate the effect of fibers on the hardened properties, the 56 days properties are normalized with respect to the Control mixture (SCC) and the results are presented in Figs. 8-12. As seen from these figures, the most significant changes were observed on the flexural strength, splitting tensile strength and later on the compressive strength. On the other hand, UPV did not seem to be affected by the size of fibers. However, the UPV could be used to assess the hardening of the SCC mixtures. It was clear from Fig. 12 that as hydration continued, the UPVs increased for all the SCC and FRSCC mixtures.

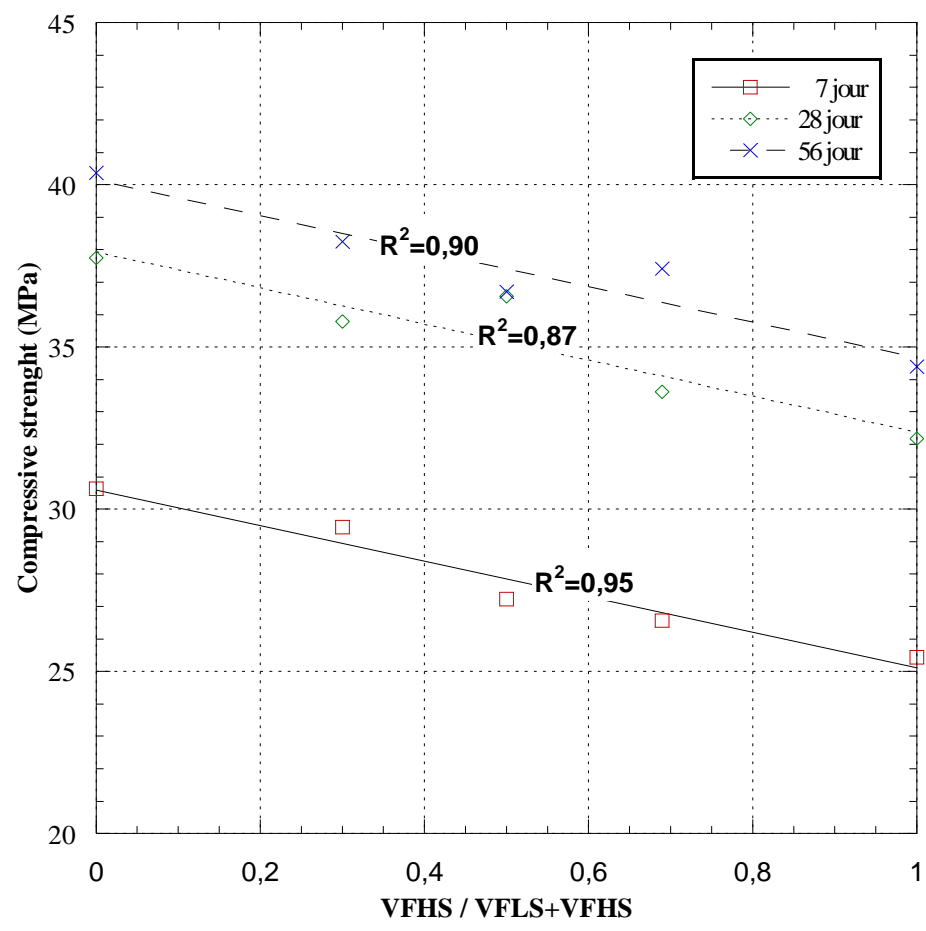

Fig 8. Effect of hybrid steel fibers on the compressive strength. 


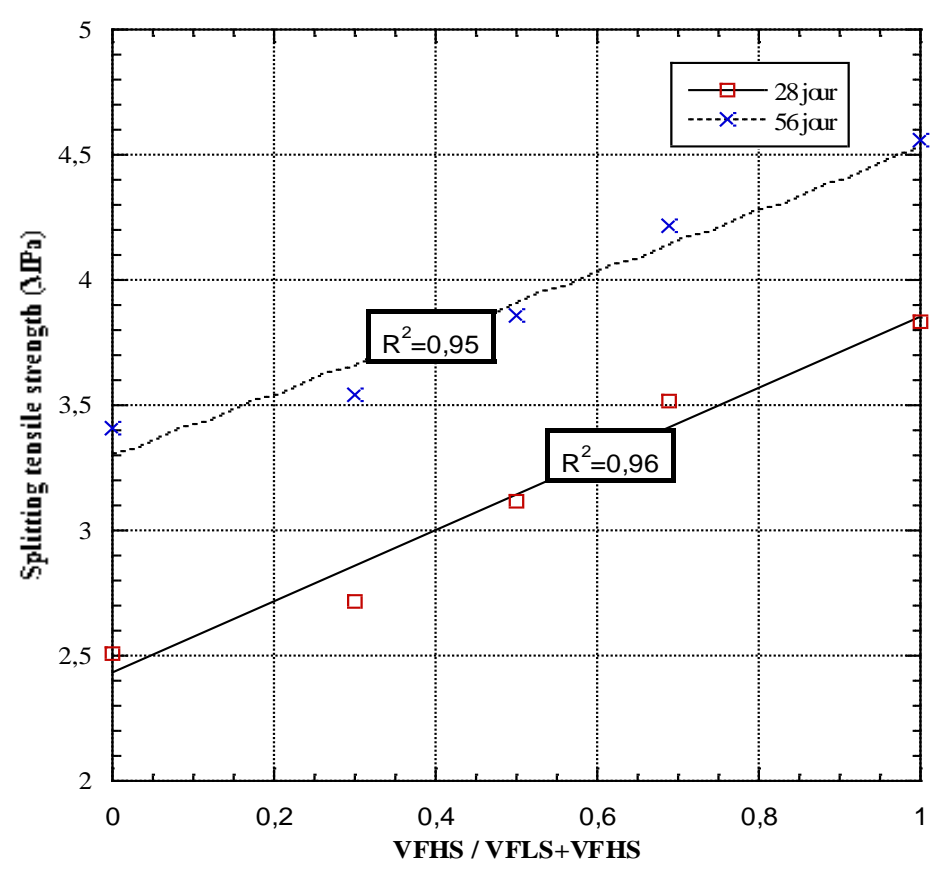

Fig 9. Effect of hybrid steel fibers on the splitting tensile strength.

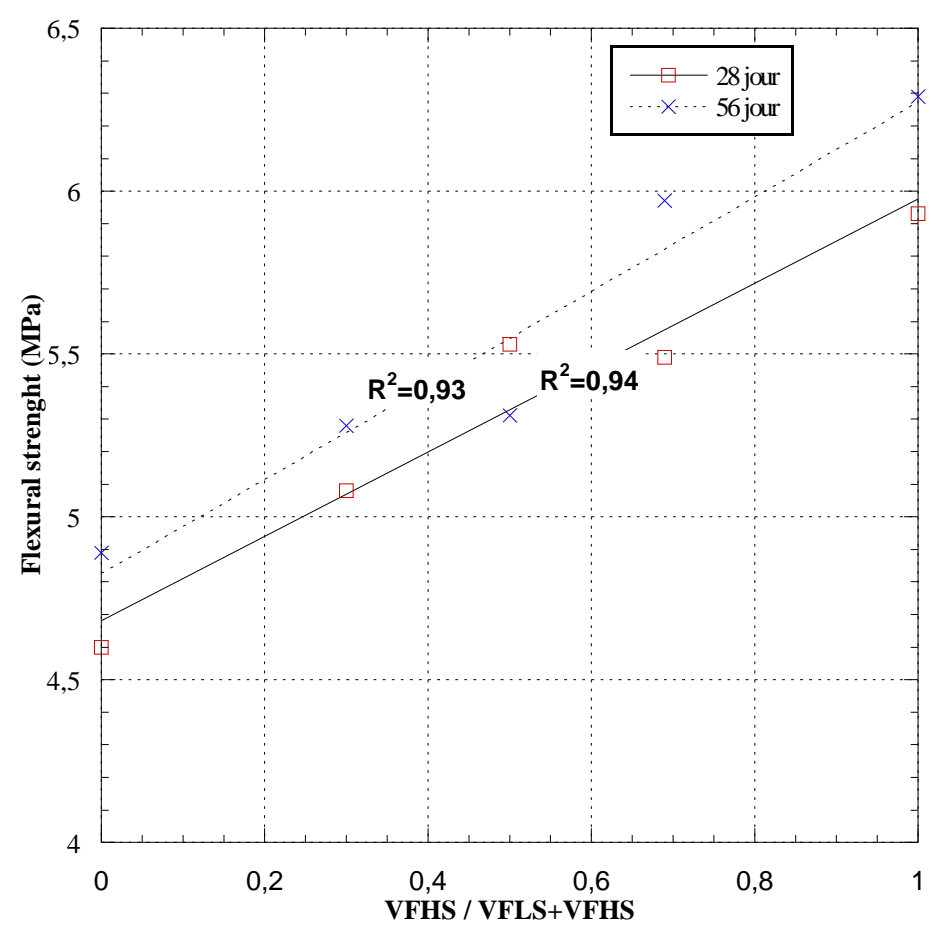

Fig 10. Effect of steel fibers on the flexural strength.

Fiber inclusion did not significantly affect the measured mechanical properties. However, as seen in Fig. 9 and Fig.10, as the volumetric ratio of the LS type fibers increased the compressive strength increased. This was due to the relatively small dimensions of LS type fibers, which gave these fibers the ability to delay the micro-crack formation and to arrest and prevent their propagation afterwards up to a certain extent. Another explanation to the increase in the compressive strength could be the decrease of fresh properties which decreased as the amount of HS type fibers increased. However, when the splitting tensile strengths were examined (Fig.9), it could be seen that there was a reduction in the splitting tensile and flexural strengths as the 
volume of LS type fibers were increased or the fresh properties increased. The reduction in the splitting tensile strength was explained by the loss of the presence of HS fibers. Therefore, HS fibers were mainly responsible for the increase in tensile and flexural strengths. Otherwise, when the tensile stress is transferred to HS fibers, the transfer can arrest the propagation of macro-cracks and substantially improve the tensile strength of the concrete.

As presented in Fig. 11, the UPV of the SCC mixtures seemed to be unaffected by the steel fiber inclusion. Nevertheless, the UPV could be used to assess the hardening of the SCC mixtures. It was clear from Fig. 12 that as hydration continued, the UPV increased for all the SCC mixtures.

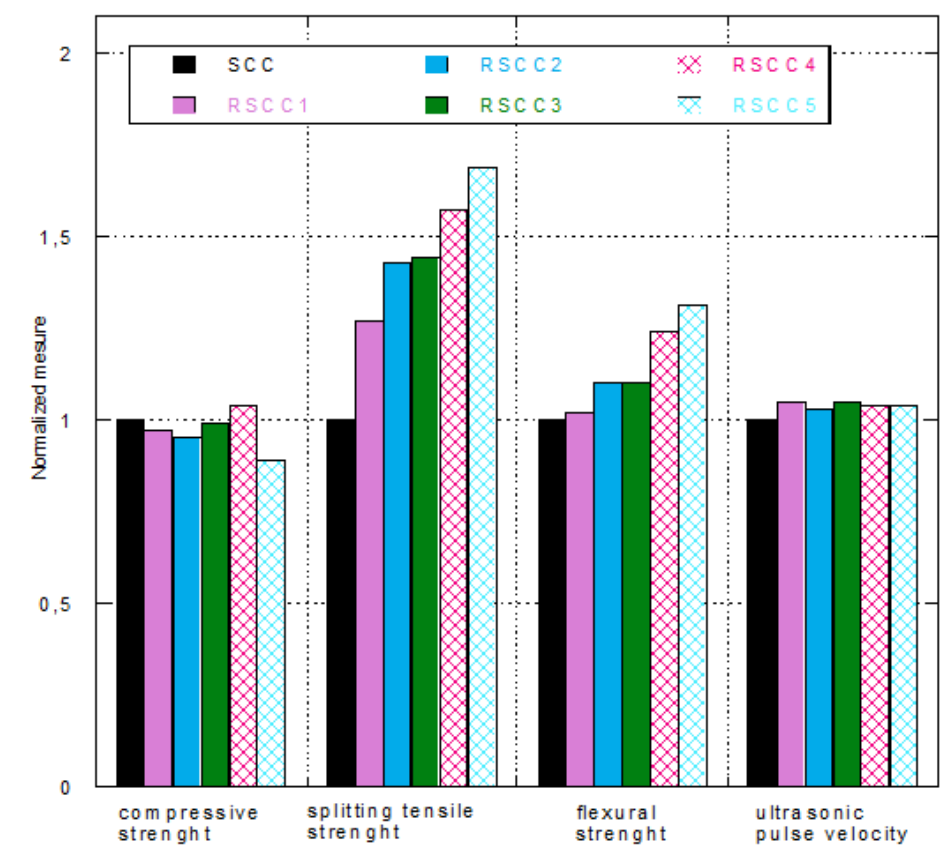

Fig 11. 56 days hardened properties of FRSCC and SCC.

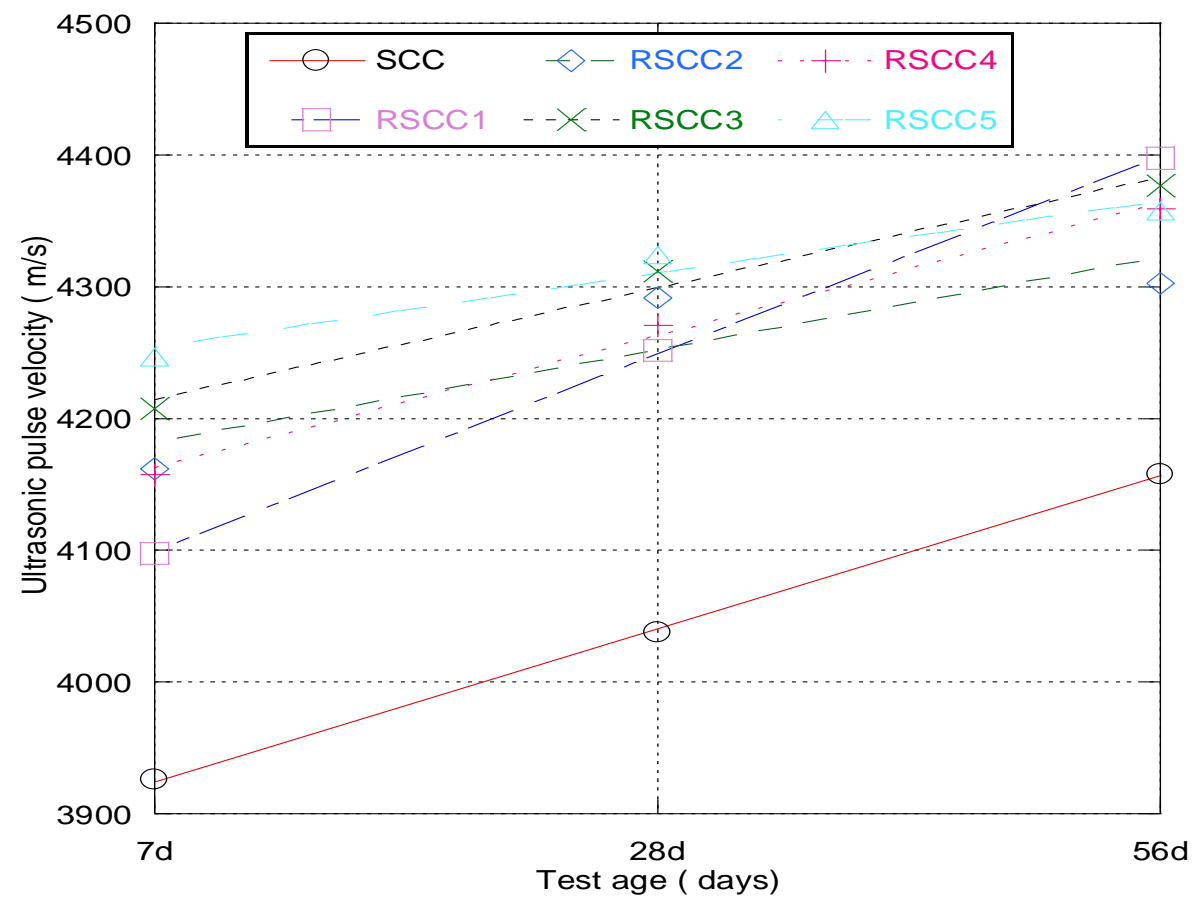

Fig 12. Strength gain of SCC mixtures. 


\section{Conclusions}

To assess the fresh and hardened properties of FRSCC, tests according to EFNARC recommendations were performed. Two types of steel fibers with different aspect ratio were investigated. The hooked end and corrugated steel fibers were used with a dosage of $60 \mathrm{~kg} / \mathrm{m}^{3}$ in the presence of high volume of marble powder. The following general conclusions can be drawn from the study presented in the paper:

- The results have shown that increasing the smaller fiber content of the concretes slightly reduced the workability of FRSCC.

- Addition of steel fibers with hooked ends reduces the compressive strength of the SCC; it can be attributed to the decrease in the workability. Therefore, concrete with the smaller fiber is denser than the one with longer fiber.

- The presence of steel fibers increased the splitting tensile strength of the SCC specimens. Steel fibers enhance the splitting tensile strength through bridging the gap between two sides of crack opening. Addition of hooked end fiber improved splitting tensile.

- Flexural strength was also improved by utilization of hooked end steel fibers. Addition of fibers improves the ultimate load capacity of the SCC beams, and it leads to an increase in the flexural strength.

- Incorporating steel fibers is essential in changing the brittle failure mode of SCCs into a more ductile one. Based on the experimental tests conducted, it can be concluded that smaller fibers in concretes function as a bridge to reduce the micro-cracks; however, they have small effect on the post-peak response of load versus displacement at the mid span of the prism. The longer fibers have no significant effect in preventing the formation of micro-cracks; however, they influence on the post-peak response part of the load versus displacement curve of the prisms, which results in high value of splitting tensile and flexural tensile.

- The effects of steel fibers on the ultrasonic pulse velocity (UPV) seemed to be negligible.

- Mechanical properties are improved by the incorporation of steel fibers in SCCs especially splitting tensile strength and flexural strength. The improvement increases as the longer fiber volume fraction investigated in this study increases.

\section{References}

AFNOR, XP P 18-540 Standard (1997). Granulats: Définitions, conformité, spécifications, Association Française de Normalisation, Paris.

Ambroise J, Rols S, Pera J (2001). Properties of self-leveling concrete reinforced by steel fibers. In Proceedings of $43^{\text {rd }}$ Brazilian Congress of the Concrete (IBRACON), Brazil.

Barr B, Gettu R, Al-Oraimi S K A, Bryars L S (1996). Toughness measurement-the need to think again. Cement and Concrete Composites, 18(4), 281-97.

Brouwers H J H, Radix H J (2005). Self-compacting concrete: theoretical and experimental study. Cement and Concrete Research, 35(11), 2116-36.

Corinaldesi V, Moriconi G (2004). Durable fiber reinforced self-compacting concrete. Cement and Concrete Research, 34(2), 249-54.

Cunha V M, Barros J A, Sena-Cruz J M (2009). Pullout behavior of steel fibers in self-compacting concrete. Journal of Materials in Civil Engineering, 22(1), 1-9.

Dhonde H B, Mo Y L, Hsu T T, Vogel J (2007). Fresh and hardened properties of self-consolidating fiberreinforced concrete. ACI materials journal, 104(5), 491-500.

Ding Y, You Z, Jalali S (2010). Hybrid fiber influence on strength and toughness of RC beams. Composite Structures, 92(9), 2083-9. 
Ding Y, You Z, Jalali S (2011). The composite effect of steel fibres and stirrups on the shear behaviour of beams using self-consolidating concrete. Engineering Structures, 33(1), 107-17.

Domeski J (2011). Cracking moment in steel fiber reinforced concrete beams based on waste send, OVIDIUS. University annals - costantza, series civil engineering, XIII(13):29-34.

EFNARC (2005). European guidelines for self-compacting concrete: Specification, production and use. Selfcompacting concrete, European Project Group.

Elkhadiri I, Diouri A, Boukhari A, Aride J, Puertas F (2002). Mechanical behaviour of various mortars made by combined fly ash and limestone in Moroccan Portland cement. Cement and Concrete Research, 32(10), 1597-603.

EN 12390-2 (2001). Testing hardened concrete - Part 2: Making and curing specimens for strength tests.

EN 12390-3 (2001). Testing hardened concrete - Part 3: Compressive strength of test specimens.

EN 12390-5 (2001). Testing hardened concrete - Part 5: Flexure strength of test specimens.

EN 12390-6 (2001). Testing hardened concrete - Part 6: Splitting tensile strength of test specimens.

EN 12504-4 (2005). Testing hardened concrete - Part 4: Ultrasonic pulse velocity of test specimens.

Greenough T, Nehdi M (2008). Shear behavior of fiber-reinforced self-consolidating concrete slender beams. ACI materials Journal, 105(5), 468-77

Katzer J (2008). Properties of precast SFRCC beams under harmonic load. Science and Engineering of Composite Materials, 15(2), 107-20.

Khayat K H, Guizani Z (1997). Use of viscosity-modifying admixture to enhance stability of fluid concrete. ACI Materials Journal, 94(4), 332-41.

Moriconi G, Corinaldesi V (2005). Rheological study of blended cement concrete. In proceeding: cement combinations for durable concrete, edited by Dhir RK. Harrison TA., Newlands MD. The $6^{\text {th }}$ Int. Congress on 'Global Construction: Ultimate Concrete Opportunities'. Thomas Telford, London, UK; p. 211-8.

Nagataki S, Fujiwara H (1995). Self-compacting property of highly flowable concrete. ACI Special Publication, 154, 301-14.

Okamura H, Ouchi M (2003). Self-compacting concrete. Journal of Advanced Concrete Technology, 1(1), 515.

Petit J Y, Wirquin E (2010). Effect of limestone filler content and superplasticizer dosage on rheological parameters of highly flowable mortar under light pressure conditions. Cement and Concrete Research, 40(2), 235-41.

Şahmaran M, Christianto H A, Yaman İ Ö (2006). The effect of chemical admixtures and mineral additives on the properties of self-compacting mortars. Cement and concrete composites, 28(5), 432-40.

Sahmaran M, Yaman I O (2007). Hybrid fiber reinforced self-compacting concrete with a high-volume coarse fly ash. Construction and Building Materials, 21(1), 150-6.

Srinivasa R, Sekhar T, Sravana P (2009). Durability studies on glass fibre SCC. The Indian Concrete Journal, $83(10), 44-52$.

Torrijos M C, Barragan B E, Zerbino R L (2008). Physical-mechanical properties, and mesostructure of plain and fibre reinforced self-compacting concrete. Construction and Building Materials, 22(8), 1780-8. 